\title{
ANALISIS UNJUK KERJA KOLEKTOR SURYA PELAT DATAR DENGAN PENAMBAHAN SIRIP BERLUBANG BERDIAMETER BEDA SEBAGAI NOSEL YANG DISUSUN SECARA STAGGERED
}

\author{
Ketut Astawa, I N Suarnadwipa, I GN Tenaya dan Agus Junianto \\ Program Studi Teknik Mesin, Fakultas Teknik, Universitas Udayana-Bali 80361 \\ e-mail: awatsa@yahoo.com
}

\begin{abstract}
The solar collector is a device that collects solar radiation and converts it into useful heat energy. Several types of solar collectors include the parallel flow flat plate solar collector and the perpendicular flow absorber plate solar collector. Previous design of flat plate solar collector perpendicular flow absorber plate usually uses plates with the same hole diameter. To improve the performance of this solar collector, modifications have been made by adding perforated fins with different diameters which are arranged staggeredly as an air flow channel or nozzle. The intended modification of nozzle diameter is to make the nozzle diameter size different from the large diameter near the inlet to the small diameter near the oulet and compared to the reverse nozzle position. Making the diameter of the nozzle near the inlet is larger than the diameter of the hole near the outlet aims to make the mass flow of air passing through the hole near the inlet larger, so that the flow of air masses experiences more heat transfer while the diameter of the hole near the outlet is made small is to reduce the mass flow of air which is wasted faster through the outlet channel. With the variation of the hole diameter from large to small, it is expected that the heat transfer that occurs in the solar collector will be more optimal, but it should also be seen in the reverse position. The research was carried out experimentally. The results of his research show that the useful energy and efficiency of solar collectors with large to small diameter slotted fins are higher than those with small to large diameter slotted fins.
\end{abstract}

Keywords: Flat plate solar collector, perforated fin, staggered.

\section{PENDAHULUAN}

\section{Latar Belakang}

Kolektor surya adalah sebuah alat yang berfungsi untuk mengumpulkan radiasi matahari dan mengubahnya menjadi energi kalor yang berguna. Beberapa tipe kolektor surya diantaranya adalah kolektor surya pelat datar aliran paralel dan kolektor surya pelat datar aliran tegak lurus pelat penyerap. Desain kolektor surya pelat datar aliran tegak lurus pelat penyerap sebelumnya biasanya menggunakan pelat dengan diameter lubang yang sama. Untuk meningkatkan performansi kolektor surya ini dilakukan modifikasi dengan penambahan sirip berlubang dengan diameter berbeda yang disusun secara staggered sebagai saluran aliran udara atau Nosel.

Prinsip kerja kolektor surya plat penyerap adalah memindahkan radiasi matahari ke fluida kerja. Radiasi matahari yang jatuh pada cover kaca sebagian akan langsung dipantulkan, sebagian akan diserap, dan sebagiannya lagi akan diteruskan ke plat penyerap. Radiasi yang sampai pada plat penyerap akan diserap panasnya oleh plat penyerap. Panas yang diserap oleh plat penyerap akan digunakan untuk memanaskan fluida kerja yang berupa udara mengalir. Proses perpindahan panas dari radiasi matahari sampai pada fluida kerja melalui tiga mekanisme perpindahan panas yaitu, konduksi, konveksi, dan radiasi. Secara konduksi, terjadi pada udara yang diam dan pada plat penyerap. Secara konveksi, terjadi antara permukaan plat penyerap dengan fluida kerja yang mengalir. Kemudian pertukaran panas radiasi terjadi di atas penutup transparan, di antara penutup transparan dengan plat penyerap bagian atas, dan antara plat penyerap bagian bawah dengan permukaan isolasi.

Modifikasi diameter Nosel yang dimaksudkan adalah dengan membuat ukuran diameter nosel berbeda dari diameter besar dekat inlet ke diameter kecil dekat oulet dan dibandingkan dengan posisi nosel sebaliknya. Pembuatan diameter Nosel dekat inlet lebih besar dibandingkan diameter lubang dekat outlet ini bertujuan untuk membuat aliran massa udara yang melewati lubang dekat inlet lebih besar sehingga aliran massa udara lebih banyak mengalami perpindahan panas sedangkan pada diameter lubang dekat outlet dibuat kecil adalah untuk mengurangi aliran massa udara yang terbuang lebih cepat melalui saluran outlet. Dengan variasi diameter lubang dari besar 
ke kecil ini di harapkan perpindahan panas yang terjadi pada kolektor surya menjadi lebih optimal, namun perlu dilihat juga pada posisi sebaliknya.

\section{METODOLOGI}

Metode yang digunakan dalam penelitian ini adalah metode eksperimental. Penelitian diawali dengan pembuatan kolektor surya plat penyerap dengan aliran impinging jet yang menggunakan plat berlubang dengan diameter lubang bervariasi (dari lubang yang lebih besar ke lubang yang lebih kecil dan dari lubang yang lebih kecil ke lubang yang lebih besar) yang disusun secara paralel di bawah plat penyerap.

Diameter yang digunakan pada plat berlubang bervariasi dari diameter lubang yang lebih besar ke diameter lubang yang lebih kecil, yaitu $9 \mathrm{~cm}, 7 \mathrm{~cm}, 5 \mathrm{~cm}, 3 \mathrm{~cm}$, dan $1 \mathrm{~cm}$. Sebaliknya, pada plat berlubang bervariasi dari diameter lubang yang lebih kecil ke diameter lubang yang lebih besar, yaitu $1 \mathrm{~cm}, 3 \mathrm{~cm}, 5 \mathrm{~cm}, 7 \mathrm{~cm}$ dan $9 \mathrm{~cm}$. Kondisi udara mengalir berada di antara plat penyerap dan plat bagian bawah, sedangkan untuk kondisi udara diam berada di antara kaca bening dan plat penyerap.

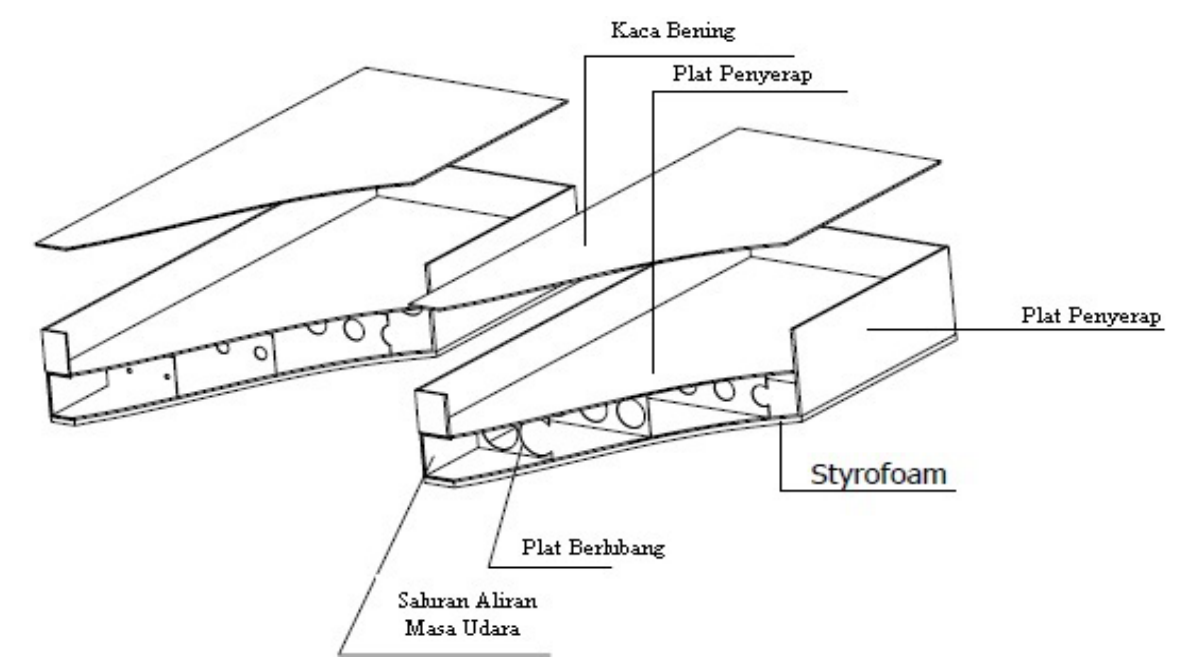

Gambar 1. Konstruksi kolektor surya menggunakan aliran impinging jet

Pada penelitian ini, kolektor surya plat datar ditambahkan plat berlubang dengan diameter lubang bervariasi. Lebar plat berlubang $\mathrm{Wp}=50 \mathrm{~cm}$, tinggi plat berlubang $\mathrm{Mp}=10 \mathrm{~cm}$, dan jarak antara plat berlubang $X=20 \mathrm{~cm}$. Diameter lubang dari diameter besar ke diameter kecil, yaitu $9 \mathrm{~cm}$, $7 \mathrm{~cm}, 5 \mathrm{~cm}, 3 \mathrm{~cm}$ dan $1 \mathrm{~cm}$.

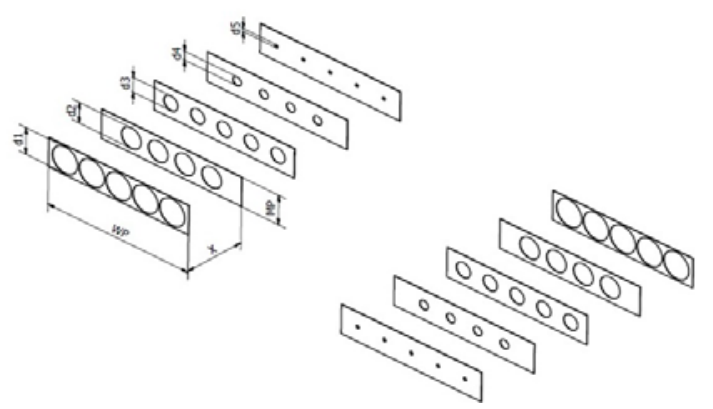

Gambar 2. Konstruksi plat berlubang dengan diameter bervariasi yang disusun secara staggered

Pengujian dilakukan dengan merangkai komponen-komponen yang diperlukan dalam pengambilan data dan meletakkan kolektor surya di tempat datar dan mendapatkan sinar matahari. Agar udara dapat mengalir di dalam kolektor dan menciptakan aliran impinging jet digunakan aliran paksa dengan bantuan blower. 


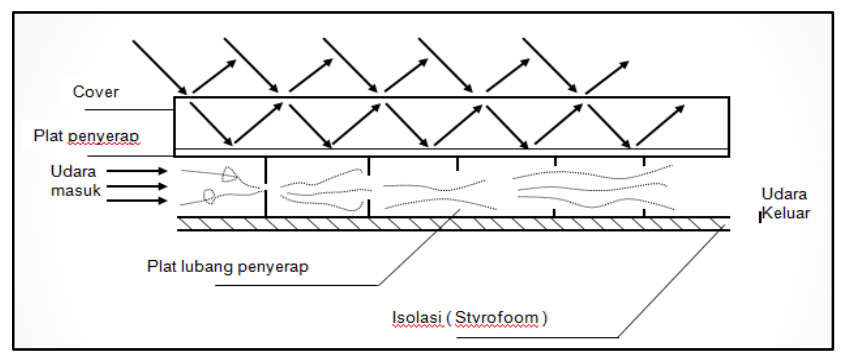

(A)

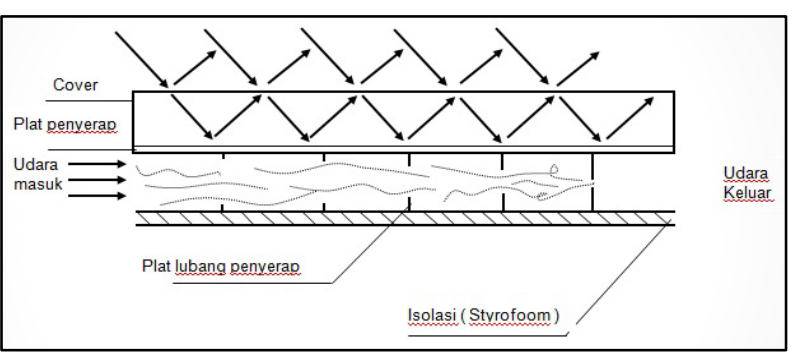

(B)

Gambar 3. Aliran udara pada kolektor surya aliran impinging jet dengan diameter lubang bervariasi dari diameter kecil ke diameter besar (A) dan sebaliknya (B)

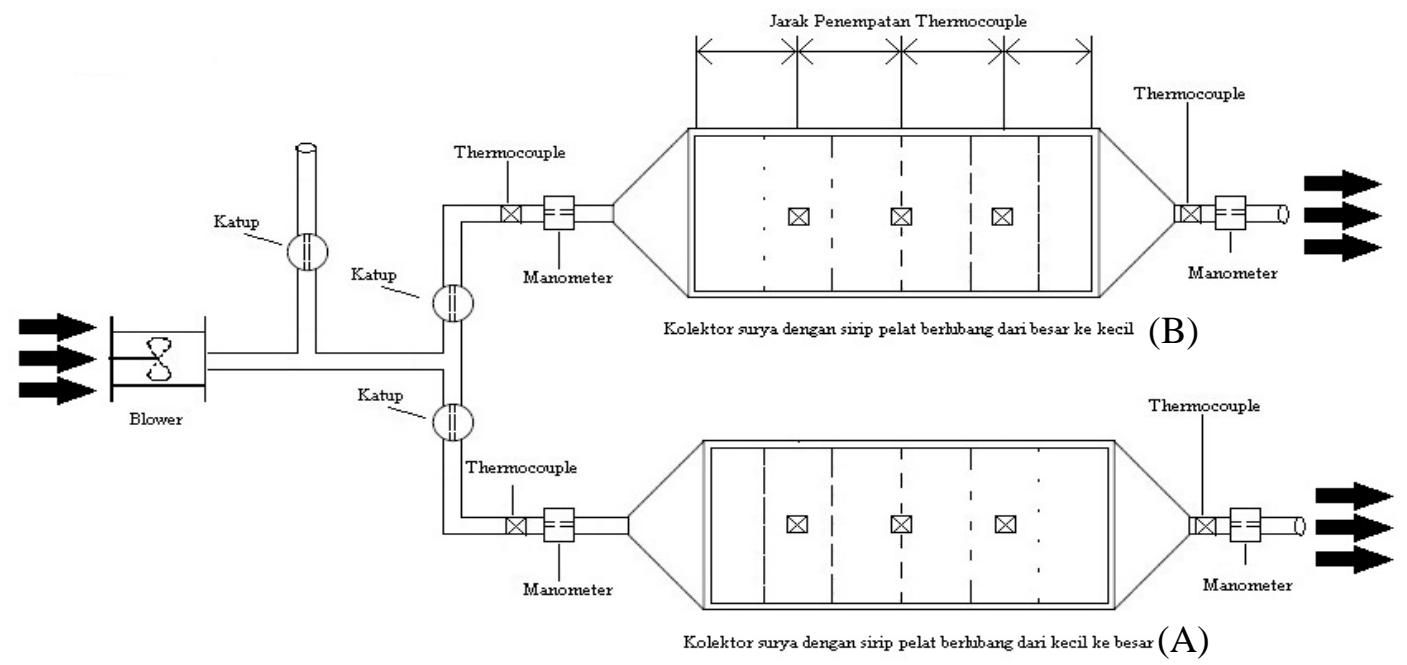

Gambar 4. Rancangan pengujian kolektor surya

Efisiensi kolektor surya merupakan perbandingan panas yang diserap oleh fluida atau energi berguna dan intensitas matahari yang mengenai kolektor. Performansi dari kolektor dapat dinyatakan dengan efisiensi thermalnya. Akan tetapi, intensitas radiasi matahari berubah terhadap waktu. Dalam penelitian ini, pengujian dilakukan hanya untuk menentukan performansi dari kolektor saja. Metode yang digunakan adalah Long term atau all-day efficiency adalah efisiensi yang dihitung dalam jangka waktu yang relatif lama (per hari). berikut:

Sehingga efisiensi aktual dari kolektor dapat ditentukan dengan menggunakan persamaan

$\eta_{a}=\frac{Q_{u, a}}{A_{c} \cdot I_{T}}$

dimana:

$\eta_{a}=$ efisiensi aktual kolektor (\%)

$Q_{u, a}=$ energi berguna kolektor sebenrnya tiap satuan luas (Watt)

$A_{c}=$ luas bidang penyerapan kolektor $\left(\mathrm{m}^{2}\right)$

$I_{T} \quad$ = radiasi surya yang jatuh pada bidang kolektor $\left(\mathrm{Watt} / \mathrm{m}^{2}\right)$

Untuk perhitungan energi yang diserap atau energi yang berguna pada kolektor surya dapat digunakan persamaan:

$\dot{Q}_{u, a}=$ m. $c_{p}\left(T_{0}-T_{i}\right)$ 
dimana:

$Q_{u, a}=$ energi berguna kolektor sebenrnya tiap satuan luas (Watt)

$\dot{m}_{\text {out }}=$ laju aliran massa fluida yang keluar dari kolektor surya $(\mathrm{kg} / \mathrm{s})$

$c_{p}=$ panas jenis fluida $(\mathrm{J} / \mathrm{kg} . \mathrm{K})$, nilai $c_{p}$ didapat dari properties fluida berdasarkan temperatur

$T_{i} \quad=$ temperatur fluida masuk $(\mathrm{K})$

$T_{0}=$ temperatur fluida keluar $(\mathrm{K})$

\section{HASIL DAN PEMBAHASAN}

Untuk mempermudah melakukan analisis maka data-data hasil pengujian dan perhitungan digambarkan dalam bentuk grafik. Grafik-grafik yang digambarkan adalah grafik performansi kolektor surya plat datar yang terdiri atas grafik hubungan $I_{T}$ terhadap waktu pada masing-masing variasi kolektor, grafik energi berguna aktual kolektor dan grafik efisiensi aktual kolektor.

Gambar 5 menunjukkan energi berguna pada kolektor dengan sirip berlubang diameter besar - kecil lebih tinggi dari pada kolektor dengan sirip berlubang diameter kecil - besar. Hal ini disebabkan karena fluida yang mengalir melalui lubang sirip berdiameter besar menuju sirip berdiameter kecil menyerap panas lebih lama sehingga temperatur keluar lebih tinggi. Energi berguna yang dihasilkan merupakan fungsi dari temperatur udara keluar kolektor. Maka besar temperatur panas keluaran pada kolektor, energi berguna yang didapat akan semakin besar.

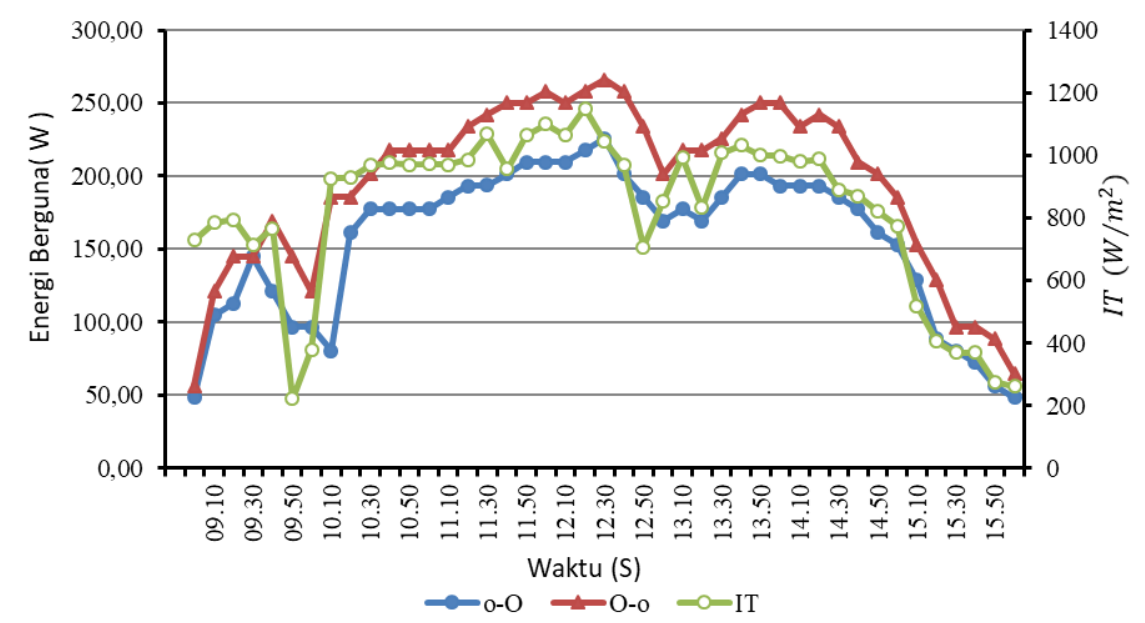

Gambar 5. Perbandingan energi berguna $\left(Q_{u, a}\right)$ terhadap waktu

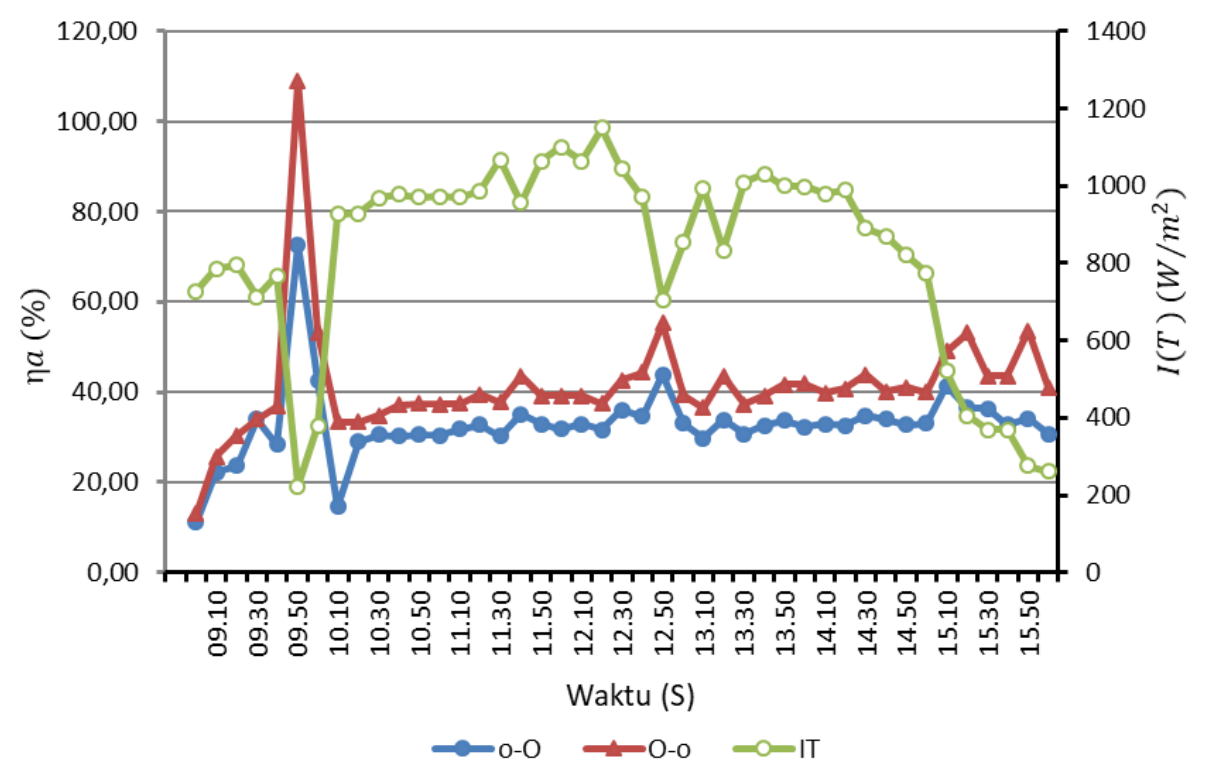

Gambar 6. Perbandingan efisiensi (na) kolektor terhadap waktu 
Gambar 6 menunjukan efisiensi pada kolektor dengan sirip berdiameter besar ke kecil lebih tinggi dibandingkan kolektor dengan sirip berdiameter kecil ke besar, hal ini disebabkan karena aliran fluida yang mengalir melalui lubang sirip berdiameter besar menuju sirip berdiameter kecil lebih banyak masuk pada sirip berdiameter besar ke kecil dan keluarnya semakin sedikit atau melambat sehingga udara dalam kolektor menyerap panas lebih lama dan temperatur udara keluar kolektor juga menjadi semakin tinggi dan efisiensinya menjadi tinggi.

Pada pukul 09:50 terjadi penurunan intensitas dan peningkatan efisiensi yg signifikan hingga 72,6256 \% pada kolektor dari diameter kecil ke besar dan 108,9514 \% pada kolektor dari diameter besar ke kecil, ini disebabkan karena pada sebelum pukul 09:50 kolektor menyimpan panas yang tersimpan pada kolektor seperti plat penyerap, sirip dan lain-lain, pada pukul 09:50 cuaca mendung mengakibatkan intensitas radiasi matahari menurun hingga $222 \mathrm{~W} / \mathrm{m}^{2}$ ), udara yang keluar dari kolektor masih pada suhu tinggi akibat dari panas yang masih tersimpan pada kolektor. Pada keadaan seperti ini kolertor sepenuhnya mengeluarkan panas ke lingkungan.

\section{SIMPULAN}

Dari hasil pengujian yang telah dilaksanakan maka dapat disimpulkan bahwa kolektor surya pelat datar dengan variasi diameter lubang dari diameter besar ke kecil menghasilkan temperatur keluar yang lebih tinggi dan menyebabkan energi bergunanya juga lebih tinggi. Selain itu, pada kolektor surya yang diameternya diletakkan secara stagerred, efisiensi dan energi berguna yang dihasilkan suhunya lebih tinggi dibandingkan dengan kolektor surya yang diameternya disusun secara line atau lurus.

\section{DAFTAR PUSTAKA}

[1] Arismunandar, W. 1995.Teknologi Rekayasa Surya. Jakarta: PT Pradnya Paramita.

[2] Duffie, J. A., and Backman. 1991. Solar Enggenering of Thermal Process, $2^{\text {nd }}$ ed. New York: John Wiley \& Sons, Inc.

[3] Holman, J.P., 1997 Heat Transfer, 8thEdition, McGraw-Hill Companies Inc., USA,

[4] Incropera, F. P., and De Witt, D. P. 1994. Fundamental of Heat and Mass Transfer. Singapore: John Wiley \& Sons, Inc.

[5] Manan, S., 2009. Energi matahari, sumber energi alternatif yang efisien, handal dan ramah lingkungan di Indonesia.Institut Teknologi Bandung.

[6] Predana, Gigih. 2015. Analisis Performansi Kolektor Surya Plat Datar Dengan Variasi Sirip Berlubang. Bali : Universitas Udayana.

[7] Sudarpa, M., 2012. Analisa performansi kolektor surya pelat atar menggunakan aliran impinging jet dengan aliran di bawah pelat berlubang dengan diameter nosel berbeda.Universitas Udayana.

[8] Wibawa, A.S., 2012. Analisa performansi kolektor surya pelat datar menggunakan aliran impinging jet dengan aliran dibawah pelat berlubang. Universitas Udayana. 